\title{
Retinal ven tıkanıklığına bağlı oluşan maküler ödem tedavisinde intravitreal deksametazon implantın erken dönem sonuçları
}

\section{Early results of the intravitreal dexamethasone implant in the treatment of macular edema due to retinal vein occlusion}

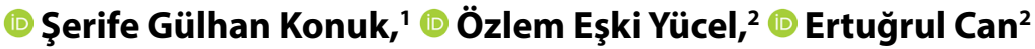 \\ 'Turhal Devlet Hastanesi, Göz Polikliniği, Tokat, Turkey \\ ${ }^{2}$ Ondokuz Mayıs Üniversitesi Tıp Fakültesi, Göz Hastalıkları Anabilim Dalı, Samsun, Turkey
}

\section{Özet}

Amaç: Santral retinal ven tıkanıklığı (SRVT) ve retinal ven dal tıkanıklığına (RVDT) bağlı oluşan maküler ödem (MÖ) tedavisinde deksametazon implantın altı aylık etkisini ve yan etkilerini değerlendirmek.

Gereç ve Yöntem: Göz Hastalıkları Kliniğinde SRVT ( $n=19)$ ve RVDT $(n=18)$ sonucu oluşan MÖ nedeniyle tek doz intravitreal dexametazon implant ile tedavi edilen 37 hasta ( $37 \mathrm{göz}$ ) çalışmaya dahil edildi. Hastaların kayıtları retrospektif olarak incelendi. En az 6 ay boyunca, aylık olarak takip edilen hastalar çalışmaya dahil edildi. Başlangıç ve tedavi sonrası her kontrolde yapılmış olan; biyomikroskopik muayene bulguları, en iyi düzeltilmiş görme keskinliği (EDGK) düzeyi ve spektral domain optik koherens tomografi (OKT) ile santral maküler kalınlık (SMK) ölçümleri ve yan etkiler kaydedilerek değerlendirildi.

Bulgular: RVDT olguları grup $1(n=18)$, SRVT olguları grup $2(n=19)$ olmak üzere hastalar 2 gruba ayrıldı. Tüm hastalarda tedavi sonrası EDGK 4. aya kadar anlamlı olarak artarken SMK değerleri anlamlı olarak azaldı $(p<0.05)$. Tedavinin 4 . ayından sonra ise EDGK değeri tedavi öncesine göre istatistiksel olarak farklı değildi. Maximum görme keskinliğindeki artış grup 2'ye kıyasla grup 1'de anlamlı olarak fazla idi. İki grup arasında ortalama SMK azalması açısından istatistiksel olarak anlamlı bir fark bulunmadı ( $p>0.05$ ). Tedavi edilen 8 hastada $(\% 21,6)$ göz içi basınç artışı görüldü.

Sonuç: SRVT ve RVDT'na ikincil maküler ödem olgularında intravitreal dexametazon implant, ilk 6 ayda anatomik ve fonksiyonel düzelme sağlamıştır. Göz içi basıncı artışı dışında yan etki görülmemiştir. Anahtar Sözcükler: Deksametazon implant; maküler ödem; retinal ven tıkanıklığı.

\begin{abstract}
Introduction: To evaluate the six-month effect and side effects of dexamethasone implant in the treatment of central retinal vein occlusion (SRVT) and retinal vein branch occlusion (RVDT) induced macular edema (MO).

Methods: Thirtyseven patients (37 eyes) who were treated with intravitreal dexamethasone implant due to SRVT $(n=19)$ and RVDT $(n=18)$ in the Ophthalmology Department were included in the study. Records of patients were reviewed retrospectively. Patients who were followed up monthly for at least 6 months were included in the study. It was performed at the beginning and after each treatment; slit-lamp biomicroscopic examination findings, best corrected visual acuity (EDGK), spectral domain optical coherence tomography (OKT) and central macular thickness (SMK) measurements were done and side effects were recorded.

Results: The patients were divided into two groups: RVDT group 1 $(n=18)$, SRVT group $2(n=19)$. In all patients, after the treatment, EDGK increased significantly up to the 4th month, whereas the values of SMK decreased significantly $(p<0.05)$. There was no significant difference between EDGK after the 4th month. The increase in maximum visual acuity was significantly higher in group 1 than 2 . There was no statistically significant difference between the two groups in terms of mean SMK reduction ( $p>0.05)$. In 8 (21.6\%) patients treated with intravitreal dexamethasone implant, intraocular pressure increased.

Discussion and Conclusion: Intravitreal dexamethasone implant provides anatomic and functional improvement in the first 6 months in patients with macular edema secondary to SRVT and RVDT. No side effects were seen except intraocular pressure.
\end{abstract}

Keywords: Dexamethasone implant; macular edema; retinal vein occlusion. 
$\mathrm{R}_{\mathrm{s}}^{\mathrm{e}}$ tina ven tıkanıklığı (RVT) diyabetik retinopatiden sonra görme azlığına en sık neden olan retinal vasküler patolojidir. [1] Santral retinal ven tıkanıklığı ve retinal ven dal tıkanıklığı olarak ikiye ayrılmaktadır. Hastalar genelde ani ağrısız görme kaybı şikâyeti ile başvururlar. Retinal ven tıkanıklığı sonrasında gelişen görme kaybının en önemli sebebi maküler ödem ve iskemidir.

RVT tedavisinde kanıtlanmış altın standart tedavi bulunmamaktadır. RVT tıkanıklığı tedavisinde laser fotokoagülasyon, medikal ve cerrahi yöntemler uygulanabilir. ${ }^{[2]}$ Tedavi seçeneklerinden grid laser sonrasında retinada oluşan skarlı alanının genişlemesi, koroidal neovaskülarizasyon, subretinal fibrozis ve görme alanı defekti gibi komplikasyonların oluştuğu görülmüş ve buna bağlı RVT'ye bağlı maküla ödemi tedavisinde ilk seçenek olmaktan çıkmıştır. Panretinal fotokoagülasyon tedavisi ise günümüzde iskemik tip RVT, neovaskülarizasyon veya neovasküler glokom gibi komlikasyonların gelişmesi durumunda yapılmaktadır. Günümüzde maküla ödemini azaltıp görme oranını artırmak için ilk tedavi seçeneği ise intravitreal steroidler ve anti-VEGF ajanlardır. İntravitreal triamsinolon aseteat hem glokom ve katarakt gibi yüksek komplikasyon riski hem de etkinliğinin 1 ay kadar olması nedeniyle yerini artık daha uzun etkili ve yan etkisi daha az olan intravitreal dexametazon implanta bırakmaktadır.

Çalışmamızın amacı, RVT'ye bağlı oluşan makula ödemi tedavisinde, intravitreal dexametazon implant sonrası anatomik ve fonksiyonel sonuçlarının değerlendirilmesi ve bu tedaviye bağlı oluşabilecek yan etkilerinin araştırılmasıdır.

\section{Gereç ve Yöntem}

Çalışmamızda Göz Hastalıkları Kliniği'nde SRVT (n: 19) veya RVDT'na ( $\mathrm{n}: 18$ ) bağlı makula ödemi bulunan, bu nedenle tek doz 0.7 mg intravitreal dexametazon implant (ozurdex ${ }^{\circledR}$; Allergan, Inc, Irvine, CA) enjeksiyonu uygulanan ve en az 6 ay izlemi olan 37 olgunun 37 gözüne ait tıbbi kayıtları retrospektif olarak incelenmiştir. En az 6 ay boyunca, aylık olarak takip edilen hastalar çalışmaya dahil edilmiştir.

Tüm olgulardan intravitrel dexametazon implant uygulaması öncesinde, ilacın ve uygulamanın yan etkileri konusunda detaylı olarak aydınlatılmış ve uygulama için onam alınmıştır. Dexametazon implant tüm olgulara steril ameliyathane şartlarında intravitreal olarak uygulanmıştır. Enjeksiyon; \%0,5 proparakain hidroklorür ve $\% 5$ povidon iodine damlatılmasını takiben alt temporal kadrandan, limbusun 3-3.5 mm gerisinden skleradan yapılmıştır Enjeksiyon sonrası tüm hastalar 5 gün süre ile \%3 ofloksasin damla kullanmışlardır. Hastalar uygulama sonrasında enjeksiyona bağlı komplikasyonlar açısın- dan gözlenmiştir. Her hasta başlangıç ve tedavi sonrası her ay kontrolleri yapılarak; biyomikroskopik muayene bulguları, en iyi düzeltilmiş görme keskinliği (EDGK) düzeyi ve spektral domain optik koherens tomografi (OKT) ile santral maküler kalınlık (SMK) ölçümleri ve yan etkiler kaydedilerek değerlendirilmiştir. Enjeksiyon öncesi ve kontrol muayenesinde makülar kalınlıkları arasında farkı değerlendirmek için Wilcoxan signed ranks testi kullanılırken, görme keskinliği değerleri arasındaki ilişki Paired t testi kullanılarak araştırılmış, $p<0.05$ değeri istatistiksel olarak anlamlı kabul edilmiştir.

\section{Bulgular}

Çalışmaya 20 (\%54.1) erkek ve 17 (\%45.9) kadın toplam 37 hasta dahil edildi. RVDT olguları grup $1(n=18)$, SRVT olguları grup $2(n=19)$ olmak üzere hastalar 2 gruba ayrıldı. Hastalar enjeksiyon sonrasında 6 ay boyunca takip edildi.

ETDRS eşeli kullanılarak elde edilen EDGK enjeksiyon öncesinde $0.159 \pm 0.13$ Snellen iken 1 . ayda $0.28 \pm 0.26$, 2. ayda $0.27 \pm 0.26$, 3. ayda $0.28 \pm 0.27,4$. ayda $0.274 \pm 0.28$, 5. ayda $0.25 \pm 0.27$, 6.ayda $0.28 \pm 0.27$ olarak bulunmuştur (Tablo 1). En iyi düzeltilmiş görme keskinliğinde tedavi öncesine göre 4. aya kadar anlamlı olarak artış tespit edilmiş, sonrasında istatistiksel olarak anlamlı fark saptanmamıştır $(p<0.05$, Paired t testi). SRVT ve RVDT grupları kendi içlerinde görme keskinliği değişimleri yönünden ayrı ayrı değerlendirildiğinde, aylara göre maksimum görme keskinliğindeki artış grup 1'de 2'ye kıyasla istatistiksel anlamlı olarak fazla idi (Tablo 2) $(p<0.05)$.

Tedavi edilen 37 gözün enjeksiyon öncesi ve 6 ay boyunca yapılan kontrollerinde yapılan OKT sonuçları karşılaştırıldığında ise SMK değerleri enjeksiyon öncesine oranla anlamlı olarak azaldığı saptanmıştır (Tablo 3 ) $(p<0.05)$. Ancak bu iki grup arasında ortalama SMK azalması açısından istatistiksel olarak anlamlı bir fark bulunmamıştır (Tablo 4).

Dexametazon intravitreal implantı ile tedavi edilen 8 hastada $(\% 21,6)$ göz içi basınç (GiB) artışı görülmüştür. Hiçbir hastada GiB artışı dışında endoftalmi, retina dekolmanı gibi uygulamaya bağlı komplikasyonlar ya da sistemik yan etki izlenmemiştir.

\section{Tartışma}

Retina ven tıkanıklığı diyabetik retinopatiden sonra ikinci sıklıkla karşılaşılan retina damar hastalığıdır ve toplumdaki prevelansı \%1-2 olduğu bildirilmiştir. 50 yaşın üstündeki kişilerde daha sık görülür ve insidansı yaşla artar. Hipertansiyon, diabetes mellitus ve ateroskleroz sonucunda RVT oluşma riski artmaktadır. ${ }^{[3,4]}$

Tablo 1. Tedavi edilen tüm olguların Snellen eşeli ile en iyi düzeltilmiş görme keskinliklerinin aylara göre karşılaştırılması

\begin{tabular}{lcccccc} 
Ay & Tedavi öncesi & $\mathbf{1}$ & $\mathbf{2}$ & $\mathbf{3}$ & $\mathbf{4}$ & $\mathbf{6}$ \\
\hline EDGK & $0.159 \pm 0.13$ & $0.281 \pm 0.26$ & $0.277 \pm 0.26$ & $0.280 \pm 0.27$ & $0.274 \pm 0.28$ & $0.247 \pm 0.27$ \\
P & & $\mathbf{0 . 0 4 *}$ & $\mathbf{0 . 0 1 7 *}$ & $\mathbf{0 . 0 3 5 *}$ & $\mathbf{0 . 0 4 7 *}$ & $0.265 \pm 0.27$ \\
& & &
\end{tabular}


Tablo 2. Dexametazon implantasyon sonrasında SRVT ve RVDT olgularında EDGK karşılaştırılması

\begin{tabular}{lccc}
\hline Ay & $\begin{array}{c}\text { RVDT } \\
(\mathbf{n = 1 8})\end{array}$ & $\begin{array}{c}\text { SRVT } \\
(\mathbf{n = 1 9 )}\end{array}$ & $\mathbf{p}$ \\
\hline 0 & $0,204 \pm 0.13$ & $0,117 \pm 0,12$ & $\mathbf{0 , 0 4 3 *}$ \\
1 & $0,388 \pm 0.27$ & $0,180 \pm 0,22$ & $\mathbf{0 , 0 1 5 ^ { * }}$ \\
3 & $0,349 \pm 0.24$ & $0,214 \pm 0,29$ & 0,144 \\
6 & $0,300 \pm 0.25$ & $0,198 \pm 0,28$ & $\mathbf{0 , 0 3 6 ^ { * }}$ \\
Maximum harf artışı & $0,200 \pm 0.17$ & $0,00 \pm 0.219$ & $\mathbf{0 , 0 4 3 *}$ \\
\hline
\end{tabular}

p: RVDT ve SRVT hastalarında dexametazon implant öncesi ve sonrasında EDGK istatiksel anlamlılık değeri; * istatiksel olarak anlamlı sonuç $(p<0.05)$.

RVT'de görme kaybının en önemli nedeni makula ödemidir. Retinal ven tıkanıklıklarına bağlı olarak oluşan maküla ödeminin tedavi protokolü tam olarak belirlenememiştir. ${ }^{[5]}$ Ancak günümüzde RVT tedavisinde intravitreal triamsinolon asetat (IVTA), intravitreal anti VEGF ve intravitreal deksametazon implant kullanılmaktadır. İntravitreal triamsinolonun makula ödemini azaltma ve görsel sonuçları iyileştirme üzerine etkili olduğu çeşitli çalışmalarda gösterilmiştir. ${ }^{[6]}$ Ancak IVTA ile göz içi basınç artışı, katarakt gelişimi ve endoftalmi gibi ciddi komplikasyonlar bildirilmiştir. ${ }^{[7,8]}$

CRUISE çalışmasında SRVT'li hastalara altı ay boyunca ayda bir intravitreal $0.3 \mathrm{mg}$ ve $0.5 \mathrm{mg}$ ranibizumab uygulanmış, 0.3 mg yapılan grupta ortalama $12.7,0.5 \mathrm{mg}$ yapılanlarda ortalama 14.9 harf kazancı saptanmıştır. ${ }^{[9]}$ BRAVO çalışmasında aynı tedavi rejimi RVDT'ye bağlı maküla ödemi olan hastalara uygulanmış, $0.3 \mathrm{mg}$ ranibizumab uygulanan hastalarda ortalama 16.6 harf, 0.5 mg yapılanlarda 18.3 harf kazancı saptanmıştır. [10] COPERNICUS çalışmasında hastalara altı ay boyunca dört haftada bir 2 mg intravitreal aflibercept uygulanmış ve altıncı ayda ortalama 17.3 harf kazancı saptanmıştır. ${ }^{[1]}$

GENEVA çalışmasında ise 1267 RVT hastasında deksametazon implantın etkinliği ve güvenilirliği araştırılmış. Bu çalışmada hastalar, $0.35 \mathrm{mg}$ ve $0.7 \mathrm{mg}$ deksametazon implant uygulanan ve sham grubu olmak üzere üç gruba ayrılmıştır. Deksametazon enjeksiyonları altı ayda bir uygulanmıştır. Bu çalışmada RVDT ve RVKT olgularının sonuçları birlikte verilmiştir. Görme keskinliğinde başlangıca göre en az 10-14 harf iyileşme oranı 30,60 ve 90. günlerde her iki deksametazon implant $(0.7 \mathrm{mg}$ ve $0.35 \mathrm{mg}$ ) grubunda ilaç yapılmayan gruba göre istatistiksel anlamlı daha yüksek saptanmıştır. Yüz sekseninci günde başlangıca göre 10-15 harf iyileşme oranı 0.7 mg deksametazon implant grubunda ilaç yapılmayan gruba göre istatistiksel
Tablo 4. Dexametazon implantasyon sonrasında SRVT ve RVDT hastalarında santral maküler kalınlık değerlerinin karşılaştırılması

\begin{tabular}{lccc}
\hline Ay & $\begin{array}{c}\text { RVDT } \\
(\mathbf{n}=\mathbf{1 8})\end{array}$ & $\begin{array}{c}\text { SRVT } \\
(\mathbf{n}=\mathbf{1 9 )}\end{array}$ & $\mathbf{p}$ \\
\hline 1 & $286 \pm 118 \mu$ & $319 \pm 194 \mu$ & $\mathbf{0 . 5 4 4}$ \\
3 & $274 \pm 137 \mu$ & $365 \pm 197 \mu$ & $\mathbf{0 . 1 1 5}$ \\
6 & $321 \pm 155 \mu$ & $409 \pm 218 \mu$ & 0.167 \\
\hline p: istatiksel anlamllık değerleri; * istatiksel olarak anlamlı sonuç (p<0.05). &
\end{tabular}

anlamlı daha yüksekken; 0.35 mg deksametazon implant ile ilaç yapılmayan grup arasında istatistiksel anlamlı fark saptanmamıştır. Çalışma boyunca 0.7 mg deksametazon implant yapılan grupta, ilaçsız izlem grubuna göre ortalama görme keskinliğinde istatistiksel anlamlı iyileşme saptanmıştır. ${ }^{[12]}$ Bizim çalışmamızda da 0,7 mg deksametazon uygulanan hastaların EDGK 4. aya kadar tedavi öncesine göre artış saptandı sonrasında ise anlamlı farklılık bulunamadı.

SHASTA çalışması, dexametazon implant üzerine yürütülen çok merkezli retrospektif bir çalışmadır. 289 RVT hastasına iki ile dokuz arasında (ortalama, 3.2) deksametazon implantı uygulanmıştır. Ortalama enjeksiyon aralığı 5.6 aydı. Bu çalışmaya göre üç veya daha fazla sıra ( 0.3 logMAR veya 15 ETDRS harf) görme iyileşmesi olanların oranı RVDT hastalarında \%27.9 iken RVKT hastalarında \%20.6 bulunmuştur. Sonuç olarak çalışmada tek başına ya da diğer enjeksiyon tedavileri ile kombine edilmiş çok sayıda dexametazon implant enjeksiyonuyla tedavi edilen retinal ven tıkanıklığı hastalarında her bir enjeksiyondan sonra merkezi retina kalınlığında azalma ve görme keskinliğinde artma olmuştur. Ayrıca birden fazla implant sonrası yeni gelişebilecek olan yan etki veya güvenlik endişeleri yoktur denilmiştir. ${ }^{[5]}$

Deksametazonun etkisini ve güvenirliliğini göstermek için yapılan başka bir çalışmada 36 RVT tanılı hastanın 36 gözü prospektif olarak araştırılmış. Hastaların 16'sında SRVT, 20'sinde ise RVDT mevcutmuş. Enjeksiyondan sonra EDGK ortalamalarına bakıldığında tedavi öncesine göre 1. 2. ve 3. aylarda anlamlı artış saptamışlar. Fakat 6. ayda 3. aya göre ortalama EDGK düzeyinde istatistiksel olarak anlamlı olmayan düşme olmuştur. Ortalama SMK değerlerine bakıldığında tedavi öncesine göre 2. ayda anlamlı azalma olurken, 3. ve 6. ayda 2. aya göre SMK da istatistiksel olarak anlamlı olmayan artış saptamışlardır. ${ }^{[13]}$ Bizim çalışmamızda da uyumlu olarak SMK 6. aya kadar tedavi öncesine göre anlamlı azalma saptandı.

Tablo 3. Tüm olguların santral maküla kalınlığının aylara göre karşılaştırııması

\begin{tabular}{|c|c|c|c|c|c|c|c|}
\hline Ay & 0 & 1 & 2 & 3 & 4 & 5 & 6 \\
\hline Santral maküler kalınlık $(\mu)$ & $609 \pm 205$ & $311 \pm 154$ & $321 \pm 148$ & $330 \pm 168$ & $397 \pm 201$ & $412 \pm 214$ & $377 \pm 185$ \\
\hline $\mathrm{p}$ & $<0.001 *$ & $<0.001 *$ & $<0.001 *$ & $<0.001 *$ & $<0.001 *$ & $<0.001 *$ & $<0.001 *$ \\
\hline
\end{tabular}


Sonuç olarak SRVT ve RVDT'ye ikincil maküler ödem olgularında intravitreal dexametazon implant, anatomik ve fonksiyonel düzelme sağlamıştır. Retinal ven dal tıkanıklığı olgularında kök tıkanıklığına kıyasla daha fazla görme artışı elde edilmiştir. GiB artışı dışında yan etki görülmemiştir. EDGK artışında etki süresi 4 ay kadar sürmüştür.

\section{Çıkar çatışması: Bildirilmemiştir.}

\section{Kaynaklar}

1. Rogers $\mathrm{S}, \mathrm{Mclntosh} \mathrm{RL}$, Cheung $\mathrm{N}$ et al. The prevalence of retinal vein occlusion: pooled data from population studies from the united states, europe, asia, and australia. Ophthalmology. 2010; 117: 313-9.

2. Hoerauf H. Branch retinal vein occlusion. In: Joussen $A M, G a r d n e r$ TW, Kirchhof B, Ryan SJ, eds. Retinal Vascular Disease. Philadelphia: Springer. 2007; 467-506.

3. O'Mahoney PR, Wong DT, Ray JG. Retinal vein occlusion and traditional risk factors for atherosclerosis. Arch Ophthalmol. 2008; 126 : 692-9.

4. Cheung N, Klein R, Wang JJ et al. Traditional and novel cardiovascular risk factors for retinal vein occlusion: the multiethnic study of atherosclerosis. Invest Ophthalmol Vis Sci. 2008; 49: 4297-302.

5. Capone A Jr, Singer MA, Dodwell DG et al. Efficacy and safety of two or more dexamethasone intravitreal implant injections for treatment of macular edema related to retinal vein occlusion. Retina. 2014; 34: 342-51.

6. Chen SD, Sundaram V, Lochhead J, Patel CK. Intravitreal triamcinolone for the treatment of ischemic macular edema associated with branch retinal vein occlusion. Am J Ophthalmol. 2006; 141: 876-83.

7. Ip MS, Scott IU, VanVeldhuisen PC et al. A randomized trial comparing the efficacy and safety of intravitreal triamcinolone with observation to treat vision loss associated with macular edema secondary to central retinal vein occlusion: the Standard Care vs Corticosteroid for Retinal Vein Occlusion (SCORE) study report 5. Arch Ophthalmol. 2009; 127: 1101-14.

8. Bardak Y, Yıldızoğlu Ü, Çekiç O. İntravitreal triamsinolon asetonid enjeksiyonunun kısa ve uzun dönem yan etkileri. T Oft Gaz. 2006; 36: 416-421.

9. Campochiaro PA, Brown DM, Awh CC et al. Sustained benefits from ranibizumab for macular edema following central retinal vein occlusion: twelve-month outcomes of a phase III study. Ophthalmology. 2011; 118: 2041-9.

10. Brown DM, Campochiaro PA, Bhisitkul RB et al. Sustained benefits from ranibizumab for macular edema following branch retinal vein occlusion: 12-month outcomes of a phase III study. Ophthalmology. 2011; 118: 1594-602.

11. Brown DM, Heier JS, Clark WL et al. Intravitreal Aflibercept Injection for Macular Edema Secondary to Central Retinal Vein Occlusion: 1-Year Results From the Phase 3 COPERNICUS Study. Am J Ophthalmol. 2013; 155: 429-37.

12. Haller JA, Bandello F, Belfort R Jr et al. Randomized, Sham-Controlled Trial of Dexamethasone Intravitreal Implant in Patients with Macular Edema Due to Retinal Vein Occlusion. Ophthalmology. 2010; 117: 1134-46.

13. Michalska-Małecka K, Gaborek A, Nowak M, Halat T, Pawłowska $M$, Spiewak D. Evaluation of the effectiveness and safety of glucocorticoids intravitreal implant therapy in macular edema due to retinal vein occlusion. Clin Interv Aging. 2016; 11: 699-705. 